\title{
KEPEMIMPINAN KEPALA SEKOLAH DALAM PENYERAPAN LULUSAN BERBASIS INDUSTRI
}

\author{
Kholifatul Husna Asri ${ }^{1(*)}$, Aan Komariah ${ }^{2}$, Danny Meirawan ${ }^{3}$, Dedy Achmad Kurniady ${ }^{4}$ \\ Universitas Pendidikan Indonesia, Indonesia ${ }^{1234}$ \\ husnaasri@upi.edu ${ }^{1}$, aan_komariah@upi.edu ${ }^{2}$,dmeirawan@upi.edu ${ }^{3}$,dedy_achmad@upi.edu ${ }^{4}$
}

\begin{abstract}
Received: 05 November 2020 Tuntutan kepemimpinan kepala sekolah semakin kompleks dan Revised: 11 November 2020 dibutuhkan dalam proses penyelenggraan pendidikan kejuruan (SMK) Accepted: 27 November 2020 untuk menciptakan lulusan yang inovatif, berkualitas dan memiliki daya saing sesuai standar dan kondisi industri. Selain itu, keberanian kepala sekolah dalam mengambil risiko melakukan perubahan dan terobosanterobosan yang dibuat sebagai upaya pemenuhan penyelarasan kebutuhan dan tuntutan DUDI penting dimiliki. Penelitian ini dilakukan dengan pendekatan kualitatif untuk dapat memberikan gambaran beserta jawaban dari masalah penelitian terkait kepemimpinan kepala sekolah. Infroman penelitian yaitu 1) pemimpin, 2) wakil kepala bidang kurikulum, 3) wakil kepala bidang hubungan industri, 4) kepala program, dan 5) guru. Wawancara, dokumentasi dan observasi dilakukan sebagai pengumpulan data dalam penelitian. Hasil penelitian ini adalah kepemimpinan kepala sekolah SMKN 2 Kota Bogor dapat berperan sebagai penggerak perubahan yang mampu membangun kemitraan dengan DUDI melalui program-program sekolah berbasis indutri, sehingga mampu menyerap lulusan di berbagai perusahaan atau industri kemitraan yang telah dilaksanakan diantaranya sinkronisasi kurikulum, PKL, TEFA, UJIKOM, kelas industri, magang guru, guest teacher, BKK dan recruitment. Kesimpulan penelitian ini bahwa pengelolaan SMK dibutuhkan manajerial skill kepala sekolah dalam merespon perubahan dan perkembangan DUDI bagi kemajuan sekolah.
\end{abstract}

Keywords: Tuntutan Pemimpin; Lulusan Berkualitas; Kemitraan

(*) Corresponding Author: $\quad$ Asri, husnaasri@upi.edu, +62 81280101923

How to Cite: Asri, K. A., Komariah, A., Meirawan, D., \& Kurniady, D. A. (2021). Kepemimpinan Kepala Sekolah Dalam Penyerapan Lulusan Berbasis Industri. Research and Development Journal of Education, 7 (1), 01-10.

\section{INTRODUCTION}

Kualitas sumber daya manusia (SDM) perlu diperhatikan sebagai upaya meningkatkan daya saing tenaga kerja dalam menghadapi era globalisasi. Dalam hal ini, SDM dapat ditingkatkan melalui Sekolah Menengah Kejuruan (SMK) yang merupakan organisasi pendidikan yang memiliki kefokusan pada pembentukaan keterampilan dan kompetensi lulusan agar selaras dengan kebutuhan industri atau DUDI melalui pemberian pendidikan kewirausahaan serta membentuk life skill peserta didik (Santiyadnya, 2011; Kurniasari, 2015). UU No 20 Tahun 2003 tentang Sistem Pendidikan Nasional (Depdiknas, 2003) bahwa pendidikan kejuruan merupakan pendidikan yang mempersiapkan peserta didik untuk bekerja dalam bidang tertentu. SMK memiliki tujuan untuk mempersiapkan peserta didik dalam memasuki DUDI sesuai dengan kompetensi dan keahlian yang sesuai. Dalam hal ini, sekolah memberikan bekal sebagai penopang kehidupan peserta didik. Menurut Wijaya dan Rusyan (2018) SMK bertujuan untuk 1) memenuhi kebutuhan masyarakat akan tenaga kerja, 2) meningkatkan pilihan pendidikan 
tinggi bagi setiap peserta didik dan 3) menumbuhkan dorongan dan semangat untuk terus belajar. Suparno (2002) mengemukakan bahwa kompetensi sebagai pengetahuan, keterampilan dan nilai yang menjadi acuan dalam bertindak dan berpikir peserta didik dalam menghadapi berbagai permasalahan, serta dalam bertindak.

Fakta menunjukkan bahwa pembanguan pendidikan kejuruan masih dihadapkan pada besarnya angka pengangguran akibat adanya ketidaksesuaian dan kesenjangan anatara lulusan atau output SMK dengan DUDI dan ketersediaan lapangan kerja. Tigginya angkat pengangguran yang didominasi oleh lulusan SMK, muncul karena adanya ketidaksesuaian lulusan dan SMK dalam memenuhi kebutuhan DUDI yang terus berubah dan berkembang. (Lestari \& Pardimin, 2019). Ketidakefisienan program pendidikan SMK sesuai dengan standar dunia kerja menyebabkan lulusan tidak memiliki daya saing dan terabaikan secara sistematis. Hasil penelitian Sulipan (2004) bahwa SMK belum mampu empowering semua potensi dan sumber daua yang dimiliki sekolah. Hal ini tentu berdampak pada kepercayaan masyarakat dan DUDI terhadap kualitas pendidikan di sekolah.

Penyelenggaraan pembelajaran di SMK perlu dirancang dengan desain yang memadukan antara demand dengan lulusan yang dihasilkan oleh SMK (Sunarto dan Supriadi, 2019). Kolaborasi antara sekolah dengan DUDI menentukan keberhasilan pendidikan di SMK, terutama dalam hal pemberian masukan terkait kompetensi dan keahlian calon tenaga kerja yang sesuai dengan standar DUDI (Murnomo, 2010). Pembelajaran yang berbasis kompetensi merupakan program pembelajaran eksperimental dalam mendorong, dan mengarahkan hubungan antara teori yang dan praktik. Pendekatan pembelajaran ini dilakukan dalam upaya memberikan pengalaman belajar kepada peserta didik, sehingga memiliki kompetensi yang komprehensif sesuai dengan kebutuhan DUDI. Hal ini, senantiasa untuk mengembangkan dan memperbaharui pengetahuan dan keterampilan peserta didik secara berkelanjutan (Sutjipto, 2019).

Agar lulusan memiliki kesiapan dan kemampuan bekerja perlu dibekali dengan wawasan yang luas, keahlian sesuai dengan kompetensi, pemahaman dalam berpikir, dan good personality sebagai agen penggerak perubahan (Fajriah dan Ketut, 2017; Satriadi, 2018). Dengan memiliki lulusan yang berkualitas, tentu dapat menekan angka pengangguran (Perdana, 2018). Lulusan yang kompeten dan memiliki daya saing didukung oleh kompetensi dan keterampilan lain seperti budaya kerja, kemampuan menanggapi realita di industri, adaptif akan perkembangan dan perubahan masyarakat (Sutjipto,2019).

Mengingat peran SMK yang semakin kompleks, maka proses penyelenggaraan pendidikan yang optimal dan efektif merupakan suatu keharusan yang harus direalisasikan. Dalam mewujudkan pendidikan yang mencipatakan lulusan yang inovatif, kreatif, berdaya saing dan berkualitas, membutuhkan peran kepemimpinan dalam mempersiapkan SDM yang mampu mengisi lapangan kerja ataupun membuat tempat kerja bagi diri sendiri dan orang lain melalui pengembangan sekolah yang dipimpin. Tentunya didukung juga dengan kemauan berubah dan pola pikir dalam mengembangan sekolah. Kepemimpinan merupakan faktor utama dalam pencapaian tujuan program pendidikan dan sesuai dengan perkembangan zaman yang selalu berubah dan berkelanjutan (Halim, 2015).

Tidak bisa dipungkiri jika SMK sebagai satuan pendidikan belum oprimal dalam mempersiapkan peserta didik sebagai tenaga kerja yang berkompeten memiliki kompetensi dan keahlian sesuai tuntutan DUDI (Jubaedah, Rohaeni, Tati, 2015). Banyak faktor yang menyebabkan hal itu terjadi, salah satunya adalah peranan kepemimpinan kepala sekolah yang masih lemah dalam mengelola pendidikan di SMK. Beberapa sekolah masih nyaman dengaan dunianya saat ini, sehingga belum berani untuk mengambil keputusan dan mengambil risiko untuk pengembangan sekolah. Kepala 
sekolah masih kurang memberi perhatian secara penuh terhadap pentingnya membuat program yang mendukung dalam penyelarasan DUDI, seperti yang disampaikan oleh Dharma (2010), persoalannya, kepala sekolah masih disibukkan dengan urusan administrasi dan keuangan, sibuk mengurusi BOS dan anggaran sekolah. Banyaknya kegiatan administratif yang harus dilaksanakan, membuat kurangnya waktu untuk melaksanakan kepemimpinan yang maksimal (Direktorat PMPTK, 2010). Kurangnya kemampuan kepala sekolah sebagai manajer pun, menjadi salah satu faktor penghambat dalam kemajuan SMK. Atas dasar itu, penelitian ini mengkaji lebih dalam peranan kepemimpinan kepala sekolah dalam penyerapan lulusan yang berbasis industri sehingga sesuai dengan tuntutan tugas SMK.

\section{METHODS}

Pendekatan kualitatif sebagai metode penelitian yang dilakukan dalam penelitian ini. Data dan infromasi diperoleh untuk mendeskripsikan hasil dan menjawab permasalahan dari penelitian melalui pengumpulan data dan menyajikan informasi yang akurat. Penelitian ini dilaksanakan di SMK Negeri 2 Kota Bogor. Unit analisis dilakukan pada informan yang terkait dengan kepemimpinan kepala sekolah dalam penyerapan lulusan. Informan didapatkan dari SMKN 2 Kota Bogor terdiri dari kepala sekolah, wakasek bidang kurikulum, wakasek bidang hubungan industri, kepala program dan guru produktif.

Tabel 1.

Partisipan Penelitian

\begin{tabular}{ll}
\hline No & \multicolumn{1}{c}{ Partisipan } \\
\hline 1 & Kepala Sekolah SMK Negeri Kota Bogor \\
2 & Kepala Program Keahlian (Kaprog) \\
3 & Wakil Kepala Sekolah Bidang Kurikulum \\
4 & Wakil Kepala Sekolah Hubungan Masyarakat/Hubungan Industri \\
5 & Guru \\
\hline \multicolumn{2}{l}{ Sumber : Peneliti (2020) }
\end{tabular}

Pemilihan sumber informasi yang digunakan peneliti adalah teknik purposive sample yang bertujuan dapat memberikan pertimbangan untuk memilih informasi yang memenuhi dalam kriteria. Alat pengumpulan informasi dan data melalui sumber data primer dan sukender. Teknik pengumpulan data melalui; 1) observasi merupakan teknik pengumpulan data melalui pengamatan di lapangan yang memiliki tujuan untuk mendapatkan data informasi tentang permasalahan yang diteliti, 2) wawancara merupakan proses memperoleh keterangan melalui tanya jawab dengan informan yang terlibat dalam penelitian dan 3) dokumentasi merupakan Teknik pengumpulan data yang tidak langsung yang ditujukan pada subjek penelitian. Metode analisis data menurut Miles dan Huberman (1992) yang meliputi reduksi data, penyajian data dan penarikan kesimpulan. Secara skema dapat dilihat pada bagan sebagai berikut: 


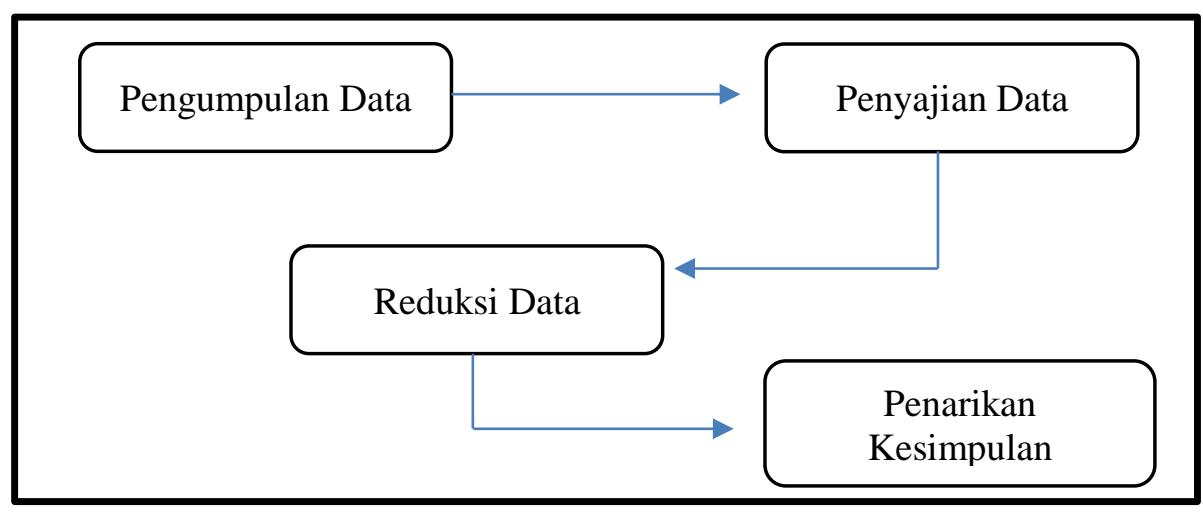

Sumber: Miles dan Huberman (1992)

Gambar 1.

Skema Analisis Data

\section{RESULTS \& DISCUSSION}

\section{Results}

Berdasarkan hasil penelitian, kepala sekolah menyadari bahwa SMK memiliki tugas dalam mencetak lulusan yang terampil, cakap, dan berkualitas untuk terlibat di dunia kerja, yang mana setiap prosesnya memiliki perubahan yang berbeda setiap saat. Atas dasar itulah, kepala sekolah SMKN 2 Kota Bogor mengembangkan peluang kerjasama dengan industri dan dunia kerja.

Kepala sekolah memaksimalkan dengan melibatkan dan memberdayakan masyarakat sekolah seperti kepala program, wakil kepala sekolah (wakasek) dan guru untuk bergotong royong membangun kuaitas sekolah melalui program-program sekolah yang disusun bersama dengan musyawarah kesepakatan bersama. Agar dapat menyusun pembelajaran yang tepat sasaran.

Kepala sekolah SMKN 2 Kota Bogor telah melakukan kerjasama dengan DUDI agar dapat mendukung tercapainya orientasi pendidikan vokasi di sekolah melalui program-program yang telah dirancang bersama. Beberapa mitra DUDI yang telah menjalin kemitraan dengan sekolah sebagai berikut;

Tabel 2.

Beberapa Daftar Mitra SMKN 2 Kota Bogor

\begin{tabular}{lll}
\hline No & \multicolumn{1}{c}{ Industri } & \multicolumn{1}{c}{ Dunia Usaha } \\
\hline 1 & Dinas Pemukiman \& Pengawasan & \\
& Bangunan Kota Bogor \\
2 & Dinas Pariwisata Kab. Bogor & \\
3 & Kecamatan Bogor Utara & \\
4 & Dinas Bina Marga Kota Bogor & \\
5 & Dinas Lalu Lintas \& Angkutan Jalan & \\
& Raya & \\
7 & Institut Pertanian Bogor & \\
8 & Lipi Biomaterial & \\
9 & Sniversitas Pakuan & CV Gubah Cipta Sasana \\
10 & & CV Arena Cipta \\
\hline
\end{tabular}




\begin{tabular}{lll}
\hline 12 & & CV Catur Prima Karya \\
13 & & CV Cakra Wisma Cipta Mandiri \\
14 & & CV Cipta Sasana Utama \\
15 & & CV Karya Lestari \\
16 & CV Guna Motor & \\
17 & PT Semangat Panca Bersaudara & \\
18 & PT Multi Konsulindo Mandiri & \\
19 & PT Inti Innovaco & Hotel Novotel Bogor \\
20 & & Hotel Pajajaran Suites - Pajajaran \\
21 & & Hotel Pajajaran Suites - Bogor Nirwana \\
22 & & Residence \\
23 & & Hotel Aston Bogor Nirwana Residence \\
24 & & Fave Hotel \\
25 & PT Honoris Industry & \\
26 & PT TOA Galva Industries & \\
27 & PT Indo Kordsa, Tbk & \\
28 & PT Bukaka Trans System & \\
29 & PT Galenium Pharmasia & \\
30 & PT Indocement & \\
Sumber : Peneliti (2020) &
\end{tabular}

Kemitraan yang telah dilaksanakan oleh sekolah dengan DUDI melalui beberapa bentuk kemitraan diantarnya sinkronisasi kurikulum, program praktek kerja industri bagi peserta didik, praktek industri bagi guru, guest teacher, bursa kerja khusus (BKK), teaching factory, mini industri, kelas industri,LSP, uji kompetensi dan recruitment. Melalui kemitraan dengan DUDI, kepala sekolah hal pertama yang dilakukan adalah sinkronisasi dan validasi kurikulum yang dibantu oleh wakasek kurikulum. Kurikulum yang dihasilkan memiliki muatan yang sesuai dan selaras dengan standar atau ketentuan DUDI. Kurikulum disesuaikan dengan keadaan real sekolah, dan kebutuhan DUDI. Kurikulum SMKN 2 Kota Bogor mengacu pada prinsip kurikulum yang berbasis kompetensi peserta didik.

Pendekatan dan terobosan yang dilakukan kepala sekolah merupakan hal urgen untuk mengembangkan sekolah sesuai dengan kebutuhan dan kondisi DUDI. Menurut Waka kurikulum SMKN 2 Kota Bogor, kurikulum ini dapat menjembatani kesenjangan yang terjadi antara DUDI dengan sekolah, agar dapat melahirkan lulusan yang dapat terserap di industri. Pada sinkronisasi ini akan menghasilkan standar lulusan, silabus, RPP dan lainnya. Sehingga dapat menciptakan dan membangun proses pembelajaran yang berbasis industri. Telah terumuskannya kurikulum yang sesuai dan relevan dengan DUDI, program-program lainnya akan terlaksana.

Penyiapan peserta didik sebagai tenaga kerja yang kompeten, kepala sekolah SMKN 2 Kota Bogor merealisasikan program kemitraan yang fokus pada hard skills dan soft skill peserta didik sesuai dengan tuntutan DUDI. Menurut Wakil Kepala Sekolah Bidang Humas bahwa penanaman nilai-nilai etika-soft skill sangat penting bagi peserta didikm serta dibekali dan dibarengi dengan kompetensi soft skill. Hal ini memiliki tujuan untuk memperoleh kesesuaian antara SMK dengan DUDI.

Berdasarkan hasil wawancara bahwa proses pembelajaran SMKN 2 Kota Bogor mengacu pada praktik dan teori. Dalam hal ini, kepala sekolah memiliki peranan untuk mengelola guru dalam proses belajar mengajar di kelas. Pembelajaran yang berfokus pada keterampilan dan kompetensi peserta didik diantaranya (1) teaching factory (TEFA), program ini merupakan bentuk pembelajaran yang berbasis industri dengan menghasilkan produk yang bisa dipakai oleh industri atau kalangan umum. Peserta didik dipersiapkan dalam pemenuhan tenaga kerja yang memenuhi persyaratan kompetensi, kemudian 
peserta didik diajarkan kompetensi dan dibiasakan dengan budaya kerja di industri selama di sekolah, agar peserta didik setelah lulus tidak merasa kaku karna sudah terbiasa melakukan tugas kerja industri saat di sekolah. (2) praktek kerja industri (prakerin), SMKN 2 Kota Bogor telah banyak melakukan kerjasama pelaksanaan prakerin dengan berbagai industri yang telah tertuang dalam Memorendum of understanding (MoU), dan (3) kelas industri, merupakan kerjasama antara SMK dengan DUDI untuk membantu peserta didik agar memperoleh pekerjaan setelah selesai sekolah.

Berdasarkan persentase hasil wawancara,dapat dilihat dari gambar di bawah ini;

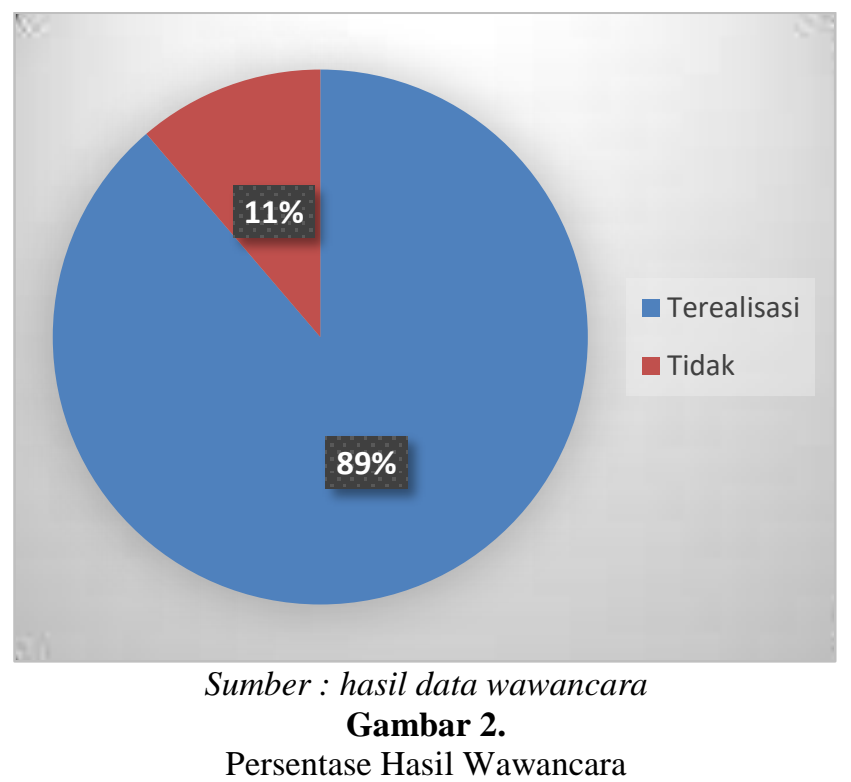

Dalam persentase hasil wawancara di atas, $89 \%$ responden menyatakan bahwa program di sekolah telah terealisasi dan $11 \%$ menyatakan jika program belum terealisasikan. Menurut guru SMKN Kota Bogor, belum teralisasikannya dengan baik karna masih belum mendukung secara maksimal fasilitas yang ada di sekolah.

Walapun begitu, Kepala sekolah SMKN 2 Kota Bogor terus mengembangkan peningkatan kualitas sekolah dengan melakukan kemitraan melalui pemberian alat praktek. Sebagai upaya meminimalisir kekurangan fasilitas yang mendukung kegiatan belajar di sekolah. Menurut wakasek Hubin, lingkup keterlibatan DUDI dalam hal penyediaan sarana prasarana sangat penting,oleh karena itu kepala sekolah terus melakukan upaya kerjasama dengan DUDI terkait sarana prasarana tersebut.

Selain itu juga, kepala sekolah SMKN 2 Kota Bogor memberikan pelatihanpelatihan kepada guru sebagai pendidik untuk meningkatkan kualitas kompetensi dan keterampilan yang dimiliki agar sesuai dengan kondisi DUDI. Kepala sekolah menyadari bahwa DUDI merupakan elemen penting dalam mendukung program SMK dan memiliki pengaruh yang cukup dominan dalam penyerasan lulusan. Sehingga diperlukan keselarasan antara SMKN 2 Kota Bogor dengan DUDI sebagai mitra.

Keberhasilan terealisasikannya program dan kegiatan di sekolah sebagai upaya persiapan peserta didik untuk siap bekerja dengan memiliki bekal kompetensi, keterampilan, keahlian dan pengetahuan berdampak positif bagi sekolah. Dari dokumen penelitian keterserapan lulusan SMKN 2 Kota Bogor, dapat tergambarkan sebagai berikut; 


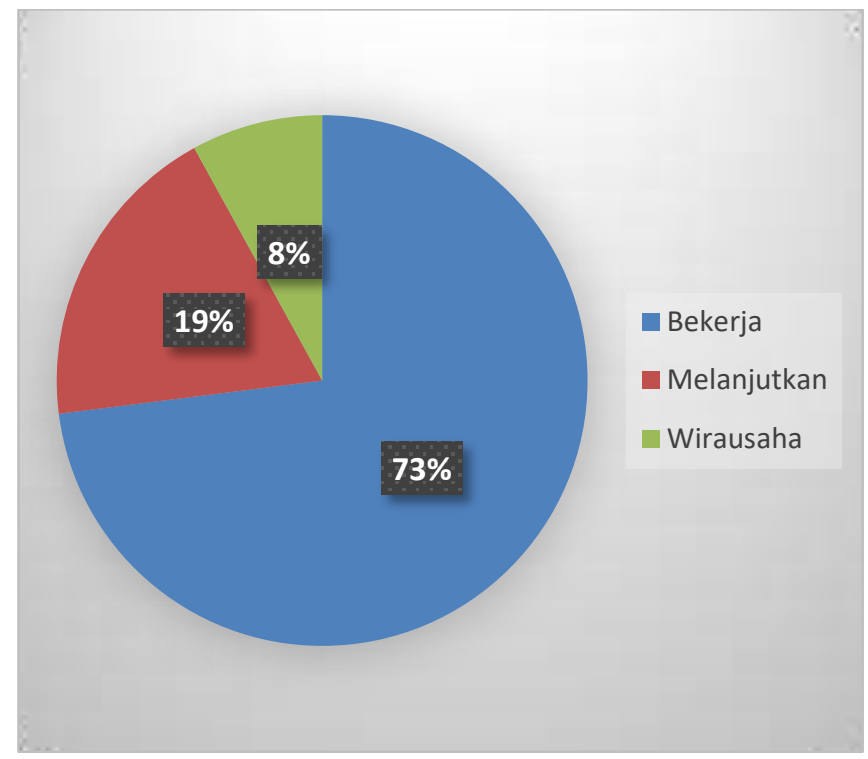

Sumber : hasil data wawancara

Gambar 3.

Persentase Hasil Wawancara

Berdasarkan persentase di atas $73 \%$ peserta didik telah terserap dunia kerja dan tersebar diberbagai jenis industri. Keterserapan lulusan yang bekerja sesuai dengan kompetensi keahlian yang dimiliki peserta didik. Dari hasil temuan peneliti, ditemukan bahwa kepala sekolah SMKN 2 Kota Bogor sebagai penggerak perubahan, harus memiliki keberanian yang besar dalam melakukan perubahan-perubahan melalui terobosan program kerja sebagai upaya menjawab tantangan DUDI, kegiatan ini dilakukan bersama guru dan stakeholders lainnya dalam proses transformasi sekolah yang menjadi wadah peserta didik mengeluarkan bakat dan passion yang dimiliki.

\section{Discussion}

Dapat dikatakan, upaya penyerapan lulusan diberbagai industri membutuhkan leader yang mampu menjadi terdepan dalam melaksanakan terobosan di sekolah. Dalam memimpin kepala sekolah diharuskan memiliki keterampilan, kemampuan, kreatif, aktif, cerdas dalam bertindak sehingga mampu mengembangkan sekolah dan memberikan perubahan yang baik (Bungin, 2011; Nasruji,2017). Selanjutnya, kepemimpinan diharapkan memiliki pengaruh, mampu memotivasi, mensuport, membimbing, memberikan arahan dan mengelola SDM sekolah untuk mengembangkan program sekolah (Bush dan Mrianne, 2000; Sulistyorini, 2008). Kepala sekolah memiliki karakter yang kuat yang dapat membawa manfaat besar bagi sekolah dan memiliki kemampuan mengelola sekolah dalam menghadapi perubahan lingkungan industri. Kepala sekolah sebagai penggerak perubahan dituntut untuk mampu menjadi katalisator di dalam sekolah. Kepala sekolah harus mampu mengenali hambatan-hambatan yang mungkin dihadapi oleh sekolah, memahami perubahan industri yang berdampak pada sekolah, dengan demikian, kepala sekolah mampu mencegah dan menangani perubahan yang terjadi. Senada dengan Villiers (2010) bahwa perlu menyeimbangan keterampilan teknis dan non-tekni untuk menghadapi perubahan lingkungan industri. Karena kebutuhan yang 
berbeda dari industri mengharuskan sekolah untuk melakukan perubahan dan terus berkontribusi dalam DUI.

Menurut Samsudi (2014) ciri dari SMK yaitu pengelolaan yang selaras kebutuhan industri. Pendidikan vokasi menekankan pada kebisaan dan keterampilan peserta didik (Ilham, et al, 2019). Pernyataan ini menegaskan bahwa individu yang terlibat dalam pendidikan vokasi memiliki knowledge dan skill yang baik dalam menguasai suatu bidang pekerjaan. Untuk mencapai kompetensi yang baik bagi setiap peseerta didik, tentu dibutuhkan pengelolaan yang matang dan interaksi yang baik pula.

Kepala sekolah SMKN 2 Kota Bogor mampu menyesesuaikan dan menyelaraskan dengan tujuan SMK dalam hal pemenuhan kebutuhan pasar atau DUDI melalui sinkronisasi kurikulum. Sinkronisasi kurikulum merupakan usaha bersama antara sekolah dengan DUDI untuk menyusun dan mengembangkan kurikulum sekolah yang sesuai dan selaras dengan kompetensi DUDI.

Dalam upaya penyerapan lulusan, kepala sekolah melakukan kerjasama dengan DUDI agar selaras dengan kebutuhan dan tuntutan industri di masa kini dan mendatang. Dalam upaya relevansi pendidikan dan meningkatkan keterampilan lulusan yang selaras kebutuhan DUDI diperlukan menciptakan dan memperkuat kemitraan dengan DUDI. Kemitraan ini meliputi pendidikan dan pelatihan bagi guru dan peserta didik yang sesuai dengan kebutuhan sekolah dan DUDI (Perdana, 2019). Membangun kemitraan dengan DUDI sangat penting agar lulusan dapat terserap ke dunia kerja. Pendidikan yang mengacu pada tuntutan kebutuhan DUDI (Murnomo, 2010; Sutrisno \& Ixtiarto, 2016). Kemitraan yang terjalin merupakan satu kesatuan upaya yang terus menerus dilakukan untuk mencapai tujuan bersama dengan berbagai tanggung jawab satu sama lain. Selanjutnya Abuzar (2011) menyampaikan bahwa SMK dengan DUDI melalui penyelarasan kondisi dan keadaan DUDI dapat memberikan manfaat diantaranya 1) memberikan pengalaman secara langsung kepada peserta didik gambaran keadaan, situasi, lingkungan dan budaya kerja yang ada, 2) memberikan semangat dorongan pada peserta didik untuk berkreatifitas lebih banyak dan mampu menemukan sesuatu yang baru dari pengalaman tersebut, 3) meningkatkan kualitas lulusan dengan bekal kedisiplinan yang ditanamkan dan dipertahankan secara konsisten, 4) memudahkan merancang kurikulum beserta program pemenuhan tuntutan DUDI.

Dengan adanya kemitraan yang dibangun antara SMK dengan DUDI akan menghasilkan suatu hubungan yang baik. Kemitraan antara SMKN Kota Bogor dan DUDI sesuai tujuan revitalisasi SMK dalam rangka peningkatan mutu lulusan SMK. Dalam Inpres tersebut, kepala sekolah menekankan bahwa diperlukan kerjsama dengan DUDI untuk menyelaraskan antara program di sekolah dengan tuntutan DUDI. Sehingga terciptanya perilaku kerja pada peserta didik. Pelaksanaan kemitraan harus menguntungkan satu sama lain guna mendukung terealisasinya tujuan sekolah (Yulianti dan Budi, 2014). Program-program penyelerasan sesuai kebutuhan industri dioptimalkan sedemikian rupa didukung dengan struktur kurikulum yang melibatkan DUDI melalui kemitraan dan proses belajar mengajar mengarah pada penguatan kompetensi yang dibutuhkan DUDI. sehingga lulusan terserap di DUDI dengan bekali keahlian yang dimiliki. Artinya lulusan memiliki keahlian sesuai dengan tuntutan kebutuhan DUDI, serta mampu mengembangkan potensi dirinya (Direktorat PSMK, 2019).

\section{CONCLUSION}

Berdasarkan temuan penelitian yang telah disajikan di atas, dapat ditarik kesimpulan bahwa penyerapan lulusan diberbagai perusahaan dan industri didukung dengan kebisaan dan kesanggupan kepala sekolah dalam merespon perkembangan DUDI 
secara dinamis dan responsif. Kemudian, kepala sekolah diharuskan memiliki keterampilan dan kemampuan manajerial dalam pengelolaan sekolah yang fokus pada kebutuhan industri. Hal ini dilaksanakan melalui sisi sinkronisasi kurikulum, pembelajaran industri, SDM sekolah yang terampil, dan fasilitas yang mendukung.

Kajian ini mengimplementasikan bahwa SMK dapat melahirkan lulusan yang memiliki attitude, keterampilan, dan disiplin, didukung dengan keterampilan kepala sekolah dan keberanian dalam memanfaatkan peluang yang dapat mengembangkan sekolah.

\section{ACKNOWLEDGEMENT}

Saya sangat berterima kasih kepada professor saya atas dukungan, inspirasi dan bimbingan yang baik.

\section{REFERENCES}

Abuzar, H. (2011). Membangun Sinergi SMK Dengan Dunia Usaha Melalui Link And Match Sebagai Pola Kemitraan.

Bungin, Burhan. (2011). Sosiologi Komunikasi. Jakarta: PT. Kencana.

Cece Wijaya \& Tabrani Rusyan. (2018). Kemampuandasar Guru Dalam Proses Belajar Mengajar Dasar Guru Dalam Proses Belajar Mengajar. Bandung: PT. Remaja Rosdakarya.

Depdiknas. Undang-Undang Nomor 20 Tahun 2003 tentang Sistem Pendidikan Nasional. Jakarta.

Dharma, S. (2010). Kualitas Kepala Sekolah Harus Ditingkatan.

Direktorat PSMK. Pembiayaan Operasional Non Personalia. Jakarta: Direktorat Pembinaan Sekolah Menengah Kejuruan.

Fajriah, U N. Ketut S. (2017). Pengaruh Praktik Kerja Inustri, Motivasi Memasuki Dunia Kerja, Dan Bimbingan Karir Pada Kesiapan Kerja Siswa. Economic Education Analysis Journal, 6 (2).

Halim, Rosnarizah Abdul. (2015). Kepemimpinan Distributif, Faktor Kontekstual dan Efikasi Kendiri. Jurnal Kepemimpinan Pendidikan, 2 (4).

Ilham, et al. (2019). Efektivitas Kepemimpinan Vokasi Untuk Produktivitas Pembangunan Sumber Daya Manusia di Balai Latihan Kerja. Jurnal Ilmiah Pendidikan Kejuruan, 12(2), 107-117.

Ixtiarto, B. Sutrisno, B. (2016). Kemitraan Sekolah Menengah Kejuruan Dengan Dunia Usaha Dan Dunia Industri. Jurnal Pendidikan Ilmu Sosial, 26(1).

Jubaedah, Y., Rohaeni, N., \& Tati. (2015). Model Link and Match Dengan Pendekatan Competency Based Training Pada Pembelajaran Tata Graha di Sekolah Menengah Kejuruan.Jurnal Penelitian Pendidikan, (15), 1.

Kurniasari, Dewi. (2015). Analisis Pelaksanaan Kerjasama SMK dengan Dunia Usaha. Jurnal Pendidikan Bisnis dan Manajemen, 1(1), 1- 70.

Lestari, B. Pardimin. (2019). Manajemen Kemitraan Sekolah Dengan Dunia Usaha dan Industri Untuk Meningkatkan Kompetensi Lulusan SMK. Media Manajemen Pendidikan, 2(1).

Miles, M. B. \& Huberman, M. (1992). Analisis Data Kualitatif. Jakarta: Penerbit Universitas Indonesia.

Nasruji. (2017). Kepemimpinan Kepala Sekolah. Jurnal Program Studi Pendidikan Sejarah, 2(1), 40-53. 
Perdana, N S. (2018). Evaluasi Pelaksanaan Pembelajaran Model Teaching Factory Dalam Upaya Peningkatan Mutu Lulusan. Jurnal Serunai Administrasi Pendidikan, 7(1).

Perdana, N S. (2019). Analisis Permintaan dan Penawaran Lulusan SMK Dalam Pemenuhan Pasar Tenaga Kerja. Jurnal Ilmiah Kependidikan, 9(2), 173-181.

Samsudi. (2014). Model Kemitraan SMK dengan Du/Di untuk Mengembangkan Kewirausahaan Lulusan. Jurnal disajikan dalam Prosiding Konvensi Nasional Asosiasi Pendidikan Teknologi dan Kejuruan (APTEKINDO) ke-7. Bandung: FPTK Universitas Pendidikan Indonesia, Bandung.

Santiyadnya, N. (2011). Implementasi Uji Kompetensi dan Pengaruhnya Terhadap Kualitas Lulusan SMK Negeri Bidang Teknologi di Provinsi Bali. Jptk, Undiksha, $8(1), 1-16$.

Satriadi, et al. (2018). Pelatihan Kewirausahaan Kreatif \& Inovatif Di SMK Negeri 1 Mempura Kecamatan Mempura Kabupaten Siak. Jurnal Pengabdian Untuk Mu Negeri, Vol.2 No.1.

Sulipan, (2004). Pengelolaan Pendidikan Dan Pelatihan Berbasis Kompetensi Kejuruan Pada Sekolah Menengah Kejuruan. Abstrak Disertasi. Bandung : PPS-UPI.

Sulistyorini. (2008). Hubungan Antara Manajerial Kepala Sekolah dan IklimOrganisasi Dengan Kinerja Guru. Jurnal Ilmu Pendidikan.

Sunarto., Supriadi, D. (2019). Efektivitas Implementasi Model Pembelejaran SMK dalam Memenuhi Tantangan Revolusi Industri 4.0. Jurnal Taman Vokasi, 7(2), 190-200.

Suparno, Paul. (2002). Kompetensi Umum Lulusan Perguruan Tinggi di Masyarakat Global, Yogtakarta. Universitas Atmajaya

Sutjipto. (2019). Perancangan Kurikulum Sekolah Menengah Kejuruan Sebagai Pranata Budaya Kerja. Jurnal Pendidikan dan Kebudayaan, 4(1).

Villiers, R. D. (2010). The Incorporation of Soft Skills Into Accounting Curricula: Preparing Accounting Graduates For Their Unpredictable Futures. Meditari Accountancy Research, 18 (2), 1-22.

Wulandari, et al. (2019). Kepemimpinan Kepala Sekolah Di Era Revolusi Industri 4.0 Dalam Meningkatkan Akreditasi Sekolah. Prosiding Seminar Nasional Pendidikan, Palembang: Program Pascasarjana Universitas Pgri Palembang.

Yulianti \& Budi S. (2014). Pengelolaan Kerjasama Sekolah Dengan Dunia Usaha dan Dunia Industri (Studi Situs SMK Negeri 2 Kendal). Jurnal Pendidikan Ilmu Sosial, 24(1). 